\title{
12 Uncanny experiences as therapeutic events
}

\author{
Kia Andell, Harley Bergroth \\ and Marja-Liisa Honkasalo
}

Encounters with the 'uncanny' - or 'supernatural' as it is often labelled in Euro-American societies - are commonly conceived of as a 'premodern' (Latour, 1993) mode of experience and characteristic of cultural 'otherness' (Kapferer, 2002). However, social scientific research has shown that such experiences are also commonly reported in post-industrial, contemporary social settings (see Dein, 2012). It seems that disenchantment, as Weber (1922/1967: 139) put it, has only had a limited effect, as people's engagements with the supernatural, the magical, and the otherworldly have not vanished in technoscientific societies with highly specialised education systems (see Josephson-Storm, 2017). By uncanny experiences we refer to 'extraordinary' sensory and embodied experiences that are often unexpected, uncontrollable and quite powerful. ${ }^{1} \mathrm{Such}$ experiences range from premonitions and visions to encounters with spiritual or otherworldly beings, and from telepathic communication to contacts with the deceased.

This chapter draws upon a letter archive of reported encounters with the uncanny. The letters have been written by a diverse group of people living in Finland. Instead of embarking on a quest to determine the actuality or 'truth' of such experiences, as might be the objective in the fields of, for example, neuroscience or psychiatry, we draw from classical anthropology (Levi-Strauss, 1968; Mauss, 1902/2001) in investigating uncanny experiences and related practices as social phenomena. We approach the textual narratives through the question of how do uncanny experiences promote therapeutic knowledge production and world making. We start from the empirical observation that as part of autobiographical narratives uncanny experiences are often made sense of through their transformative and fundamental effects. We argue that the uncanny becomes meaningful - and thus quite 'real' - in the sense that it shapes one's actions, life paths and conceptions of oneself and the surrounding world in ways that often promote stability and healing.

Engagement with the uncanny has been intertwined with ameliorating practices in the healing traditions for ages. In the rich historical research on the topic, the ability to mediate between different worlds and to work with extraordinary forces is considered a crucial part of the healer's competence (Eliade, 1964; in 
Finland e.g. Honko, 1960; Siikala, 1978). Furthermore, in healing traditions the extraordinary in its various forms appears as a crucial resource for knowledge and for strengthening the bonds between people and society; here the process of healing is not limited to a patient-healer dyad but involves a multiplicity of actors, for example, other people such as fellow villagers as an audience that confirms the evidence of the ritual efficacy. The ritual healing involving the uncanny is a mechanism for bringing the effusive, transient, and fragile qualities of social relations into the light of the visible (Turner, 1968).

Due to modern medicine's marginalisation of traditional healing practices, healing by and through the uncanny is now commonly discussed through the notion of 'therapeutic culture' - a term referring to the rise of individualistic life management discourses in Euro-American societies. In particular, discussions on new spiritualities and New Age address the topic of otherworldly connections. Sociologist James Tucker (2004) has analysed what he calls the 'therapeutic theologies' of contemporary healers in the US, arguing that modern healers practice an extreme form of self-centred and hyper-individualised therapeutic culture through which the self is elevated as its own master and the individual notion of any definitive 'truths' are ultimately rejected as one is encouraged to forge one's own path in life. By reading through the healers' conceptions of the world and their social positions and lifestyles, Tucker (2004: 167) claims that such New Age practices work unlike religion because they 'do not bind people to a larger group of people or society nor require them to submit themselves to higher authority'. However, this is not necessarily the picture we encounter in the context of this research, as it seems that such experiences need not only be about being the author of one's own life, but also very much about being led and cared for, as well as about caring for others. In addition, uncanny experiences are also not only about constant change, but also about stability in the face of unpredictability, as they appear profoundly connected to the maintenance of social relationships. In this chapter we show how the uncanny can and does become part of people's therapeutic assemblages precisely because it entrenches connections and stabilities in the middle of personal, political, local and global crises.

For our analysis of the textual data, we employ a Latour-influenced framework of actor-network theory. This enables us to treat uncanny objects (i.e. beings, voices, feelings, sensations) as 'actants' that in cooperation with other actants influence the world and contribute to (re)arranging it. We ultimately argue that uncanny experiences and the narration of these experiences can be understood as 'therapeutic events', that is, as significant sequences of truthmaking in terms of the self and as sequences of actualising social (care) relations. In this chapter we will first elaborate upon our theoretical framework by relating it to the dominant neuroscientific ways of understanding uncanny experiences and by introducing the concepts of actants and events. The data and methods will then be presented in more detail. This is followed by three analytical sections, the division of which is based on our thematic reading of the letters. Finally, we will provide brief conclusions. 


\section{Uncanny experiences: cognitive anomalies or socially significant life events?}

In the wake of scientific rationalism, uncanny experiences in the 20th century have been widely understood through psychiatric discourses labelling them as pathological. In recent decades, however, neuroscientific research has had a remarkable impact on cultural conceptions and representations of such experiences. Using new imaging technologies, neuroscientific research has managed to show how uncanny experiences have an actual (i.e. visible and measurable) correlation in the brain (Raij et al., 2009; Silvanto, 2015; Mobbs \& Watt, 2011; Blanke \& Arzy, 2005). Discussions based on such research have thus emphasised experiences such as hearing voices without a visible source and out-ofbody experiences as normal instead of merely pathological. Nevertheless, the research carried out within the natural scientific paradigm still tend to treat uncanny experiences as deviant (see Schmidt, 2016) or as temporary 'error' states of an individual brain. The idea of the uncanny as an error state has been consolidated by a wide range of research within cognitive psychology (for an overview, see Rancken, 2017) ${ }^{2}$ which has also influenced seemingly different fields of research. For example, though sympathetic to the understanding of uncanny experiences as inherent in the faculty of the human mind, the phenomenologist Matthew Ratcliffe (2017) promotes the idea of the uncanny as a disturbance of the modal structure of the mind. By constructing uncanny experiences as disturbances or errors such accounts overlook the fact that these experiences may appear as highly meaningful to the experiencer and crucially affect their life in ways that sit uneasily with the idea of a mental error that needs to be corrected (see also Luhrmann, 2018).

Setting aside the conception of mental error, we argue that the narratives of uncanny encounters often construct such experiences as therapeutic instances that serve as crucial resources for self-understanding, identity construction, healing and work on one's social relations. By this we mean that in the analysed narratives, the uncanny appears as a central building block of the cultivation and craft of one's identity and one's social surroundings, no matter whether the actual encounters or happenings themselves are described as positive or unsettling; as 'natural' or 'mysterious'. In Levi-Strauss' (1968) terms, uncanny experiences are a bricolage. For example in our letter data, people often make sense of these experiences by employing various modes of knowledge, such as modern science, mysticism, parapsychology and religion. Drawing from this idea of the bricolage, we further approach the uncanny through a Latourian (2005) framework which problematises clear-cut dichotomies such as science-religion, real-not-real, naturalunnatural or human-non-human, and thus attempts to question some of the basic paradigms of scientific rationalism from which mainstream scientific accounts on uncanny experiences typically draw.

Like the social scientist Latour, several anthropologists have rejected the notion of the inanimate nature of objects, a notion which deprives objects of agency and personhood (Descola, 2013; Viveiros de Castro, 2004). The so-called 'flat 
ontology' rejects divisions between different levels of being (e.g. social-material, real-imaginary, natural-supernatural etc.). Latour has emphasised that in order to make sense of the social world, we need to consider objects - be they technical devices, human beings, ideas or words - as active participants in the course of action (Latour, 2005: 63-86); in this view, existence is not an a priori property of any 'thing', but rather it can be claimed that things exist only in the sense that they affect the world around them. Any social reality can then be said to consist not only of human action, but of (material, ideal, semantic or perhaps metaphorical) objects that afford certain actions while preventing others (e.g. a door may both suggest and enable a passage, and prevent or redirect movement) and thus very concretely act by affecting how the world works (see Latour, 1992). In this tradition, it is typical to speak of 'actants'. ${ }^{3}$ The concept of an actant denotes an attempt to surpass the human tendency to see agency or the ability to act as an exclusively human trait. Any 'thing' that affects the world is an actant, an actor in its own right.

This suggests that whenever the social scientist wishes to analyse a human practice (such as therapeutic world making), the practice in question should be made sense of as a collection of actants - an assemblage, as all actants within an assemblage make the practice what it is. Intuitively, it may be relatively easy to conceptualise human life coaches (see Yankellevich in this book) or digital self-tracking technologies (see Bergroth and Helén and Freigang in this book) as actants in the sense that such objects may (or may not) notably influence one's self-image and, most of all, they really exist in the world! However, we argue that in the sense of people's everyday therapeutic assemblages and world making, uncanny actants can be just as effective and therefore just as 'real' in shaping one's life (see also Honkasalo, 2017a).

The idea of assemblages connects to the idea that the world or reality is never fixed-in-place, but is always subject to change and becoming. Each actant in a network of actors affects the assemblage so that the assemblage contingently 'hangs together' and is, in this sense, multiple (Mol, 2002). In assemblages, different actants fall into relations with each other; they 'happen' to each other. For the purposes of this chapter, we then employ the Latourian idea of an 'event' that relates to a rupture or a happening through which the world comes to hang together in a distinct fashion. After all, everyday life is usually not characterised by a relativistic stance towards the world; human beings do constantly establish truths - or at least relatively stable conceptions - about themselves, about others, about the things they perceive and the things they practice. In Latour's (1999) philosophy of science, the concept of an event is supposed to replace the notion of a 'discovery', which implies that one could merely discover a fact for example, a fact of nature or a fact of history - which has always been there and exists irrespective of the observer, just waiting to be found. 'Events', in contrast, refer to occurrences or sequences - possibly temporally unspecific and covering a long period of time - in which actor-networks 'set up' the world and make it known in certain ways. This is to say that 'events [...] do not discover truth, but they make truth happen' (Sansi, 2013: 453). 


\section{Materials and method}

Our empirical investigation is based on an archive of over 200 unsolicited letters about people's everyday uncanny experiences. They were sent to the research project Mind and the Other (see Honkasalo 2017b) after the project gained public visibility in the Finnish media. The letters bring forth a diverse range of experiences. Some writers mention lonely experiences of intuitive thoughts, visions and weird feelings, and others speak of vivid and powerful encounters with mysterious beings or dead relatives, friends and pets. Some people recount having the obscure sense of a presence or someone touching them when no one seems to be around.

The letters in question have been sent by people from all walks of life and with diverse educational and occupational backgrounds. In contrast to some previous work on therapeutic spiritualities (e.g. Tucker, 2004; Heelas \& Woodhead, 2005), writers are often not practitioners (healers, mystics, clairvoyants, etc.) or participants in spiritual movements and well-being practices, although as will be shown through our examples, uncanny experiences have led some of them on paths of helping others. One part of the letters is from writers who are keen on finding an (scientific) explanation for particular uncanny incidents. For others the uncanny has 'always' been a part of life and the experiences are further elaborated upon in autobiographical letters. For the purposes of this chapter, we unpack three such autobiographical narratives which neatly illuminate the various therapeutic dimensions of uncanny experiences.

We read the narratives closely, combining elements of narrative studies, thematic content analysis and Latourian-inspired material semiotics. We have carried out thematic content analysis of these assemblings on a case-by-case basis, paying close attention to how different actants emerge and come together to enable therapeutic knowledge production on oneself and the world. The analysis is further informed by ethnographic studies on 'illness narratives' focusing on people's personal experiences and the subjective truths that have generally been neglected in medical accounts. Narrative approaches often draw attention to 'disruptive' (Bury, 2001) or 'exceptional' (Rancken, 2017) moments and experiences. The uncanny, especially when it occurs repeatedly, often constitutes a major instance of 'autobiographical disruption' (Bury, 1982), and thus, similarly to illness narratives, stories of uncanny experiences can be understood as narratives of disruptions which shed light on personal meanings, relations towards the world and wider cultural/societal issues (Bury, 2001, 264). Furthermore, it could be argued that uncanny experiences and their narration also serve as disruptive instances that 'make the truth happen' in terms of self-understanding and one's social reality.

We have organised the narratives analysed in this chapter under three key themes based on the idea of the therapeutic as active work one engages in: work on the self, work on the society and work on social relationships. The analysis follows this three-fold structure, and in each section we seek to illuminate one theme through one particular narrative while also seeking to link distinct narratives. Focusing on one narrator at a time enables us to concentrate on the whole of their personal narratives. This in turn allows us to grasp the processual, event-like 
nature of uncanny experiences and their therapeutic effects, as well as recognise transformations that take place in the narrators' relations to the self, others and the world through the assembling of uncanny and other actants.

\section{The uncanny and work on the self}

Joonas is a 33-year-old family man who self-identifies as a 'seeker'. He recounts that his childhood was spent in a religious home environment (his father was a priest), which he says provided him with a 'framework for interpretation of the world'. Later in life he has conducted university-level studies in theology and cultural studies of religion, and has had a long-standing interest in esoteric literature and mysticism. Joonas, like many other writers, reflects on his uncanny experiences as something that may and often do seem frightening or 'crazy', even to himself, and he ponders whether these experiences have been distorted or altered by his memory. Yet he assures the reader that the experiences have had significant effects on his life.

I regard myself as a seeker and I try to find some kind of meaning in everything that I have experienced over the years. I think of myself as a relatively normal and sane person and I have an aversion towards New Age thinking, but at the same time I cannot disregard my experiences as just some kind of underlying insanity; I rather see them as one of the most significant building blocks of my identity.

In shaping the identity of a seeker, Joonas refers to something that is common across many of the writings on uncanny experiences: that one is 'attuned' towards experiencing the uncanny or that it is a trait that has always been a part of oneself. The adoption of the identity of a seeker also seems to function as a narrative way to balance - or overcome - the evident tension between experience-based and science-based modes of knowing, for example, the labels of 'sanity' and 'insanity' that Joonas struggles with. Joonas' time in his childhood home seems to have been a crucial, temporally unspecific and longitudinal event in his becoming a seeker. In addition to living with his family, he says that he also shared his childhood home with two 'beings' that he alone was able to sense. In his letter, he describes how the presence of the 'veil-being' - a veil-like figure that communicated telepathically - was always a source of comfort. For example, Joonas describes an incident in which he was hiding under the living room table because his parents were having an argument. There, the veil-being lingered beside him and spoke to him, telling him that his parents would not be divorcing but are 'learning each other'. However, in contrast to the comforting presence of the veilbeing, there was also another being that appeared to him regularly, the 'spoolman', whose figure was that of a man with the head of a hammerhead shark and a torso of spools. Joonas mentions that one of these encounters with the spool-man happened while he was sitting on a potty in a room he shared with his brother. For him, the spool-man's presence was always a source of nervousness and anxiety. Here, the uncanny beings, as both comforting and distressing, surface as actants 
that affect the way Joonas perceives himself and produce knowledge on the world in particular situations.

However, Joonas' identity as a seeker is not only about receiving the uncanny, but also about actively seeking a connection with extrapersonal forces. For Joonas, such active (identity) work of a seeker has been evident in the form of the 'prayer'. Joonas' praying practice reflects his way of drawing from different knowledge and belief systems such as religion and mysticism. He has been engaged in such active work since he started seeing frightening visions in his early adolescence after reading the Book of Revelations in his childhood home. He describes the development of the practice as follows:

Around when I was about ten years old, I developed a recurring habit of praying. My relation to the church was sceptical and even hostile, but especially when I was walking in nature, I used to constantly talk to myself, as in my own prayer.

I vividly remember how I sat on a swing in the neighbouring yard on a summer day, feeling strong anxiety, and I prayed in a mantra-like fashion for tens of minutes that the things I dream about would not come true. I then felt a voice somewhere inside of me - not in my head but more like somewhere between my spine and the back of my head - and the voice said that everything that I've seen will come true in my lifetime but that I would be safe. It is now hard for me to define how much of that answer was the product of my own imagination and how the years that have since passed have affected my experience. However, the truth is that at that moment I felt the answer as real, and most of all comforting.

So for Joonas, praying is a practice that invokes answers that establish truths about the world and the future. This is reminiscent of how Mauss (1909/2003) understood prayer as a social practice, a rite that has efficacy in world making. Notably, for Joonas, the prayer connects to self-preservation not only through the reception of comforting knowledge about the future but also because the reception of answers to his prayers seems to have required active care for the self. For example, in Joonas' narrative, it gradually becomes evident that he has struggled with the consumption of substances such as alcohol, particularly during student years. After one of the worst months of almost non-stop binge drinking - all the while suffering from what would later be diagnosed as an ulcer - he tried praying after having not done so for several months, but could not get any answers. He writes that it was 'as if the world was sulking at me'. In his narrative, these times are characterised by frightening 'visions'; he writes that he constantly saw visions of rough and rugged 'interiors of houses', which he interpreted as places he would end up. He also writes about an incident involving a mysterious character when he was in a possibly life-threatening situation:

I was walking home from a bar, very drunk. I stopped at the corner of a closed-down store and I felt a need to lay down into the snow just for a while. 
I passed out and then woke up frightened as a tall figure in front of me shouted, 'Get up! You were not born just to die there!' I was freezing and walked home, laid down on my bed, and cried through the whole night.

We may then theorise uncanny experiences and practices as social forms or instantiations of care for - and cultivation of - the self. Uncanny experiences, such as visions of places, mysterious beings that provide comfort or traumatic experiences, and concrete, embodied 'answers' to one's prayers, are often made sense of through the effects that they impose on one's self-understanding and relation to one's actions or situations. In Joonas' narrative, uncanny experiences are therapeutic 'events' that actualise self-understanding and self-care, and by writing about himself as a 'seeker', Joonas establishes a difference to religious self-understanding (a religious person) or scientific self-understanding (a disturbed mind).

Joonas' narrative hints that uncanny experiences may be understood as a way to handle emotionally and psychologically taxing situations, to deal with fractures and turning points in one's life. In terms of comfort, what seems typical in these experiences is that they provide security in the face of the fragility of human life and insecurity about the future; for example in addition to the aforementioned examples of domestic arguments and substance abuse, Joonas' narrative of experiences connected with the uncanny involve a near-drowning incident, a decision to pursue a new line of university studies, his mother falling seriously ill and his own looming divorce, among other things. However, these experiences are not only about insecurity and uncertainty in relation to the everyday lifeworld of the individual. Uncanny experiences may also connect with wider social, political and technological frameworks and dis/continuities which induce uncertainty and chaos in relation to the future(s) of local communities, nations and even mankind as a whole. In relation to visions, Joonas writes of having seen 'chaotic nightmares' about global threats, in his words 'everything from clouds of pollution to exploding nuclear facilities'. In addition, these visions - and the accompanying anxiety - have always been partly tied to globally significant political events and ruptures such as the fall of the Soviet Union, the Gulf War, and more recently, the events in Ukraine and the Crimean Peninsula, which he says he followed almost obsessively through the media. In hindsight, Joonas writes about dreams and premonitions that have haunted him before these events actually took place. As typical in a Latourian (1999) conception of events, there is no evident causal relation between the experiences of such premonitions and actual political events (after all, it is perhaps impossible to say which comes first, the political event or the idea of related premonitions); in any case, such political upheavals are crucially connected to the sense of dis/continuity of the world as it is.

In summary, we argue that Joonas' uncanny experiences are about self-care and self-work in the face of uncertain futures and a chaotic existence. They are a social practice of coming to grips with experiences of uncertainty, powerlessness and negative states such as fear or anxiety. They may also help to handle overwhelming positive feelings and excitement. However, what sets our account of uncanny experiences apart from the basic functionalist idea of the uncanny 
happening in a time of crisis is the idea that the uncanny is not only a 'therapeutic tool' that serves a predetermined function but it is a 'real' actant in people's therapeutic assemblages, which include various actants from traditional beliefs to holy texts and from mysterious beings to political decisions and national armies. This is to say that uncanny actants are part of a complex network of actants which have established Joonas' identity. They are also a part of a self-care assemblage; as Joonas says, undefined forces - 'the other' - have been and will now always be present in his life, helping him to navigate the complexities of personal and political life although also at times invoking anxiety and other negative feelings. Thus, such experiences may well even become actively sought after. Furthermore, experiences of such 'guidance' may also detach one from self-centred ways of understanding social reality.

In Joonas' narrative, active work with the uncanny focuses on the self as he keeps these experiences mostly to himself. We will now move on to exemplify how such work can also focus on other people as uncanny experiences become a 'skill' that can be put to use for the good of others and the community.

\section{The uncanny and work on the society}

Elisa is a 58-year-old entrepreneur and former artist who has spent the last three decades of her career helping, healing and educating others as a professional massage therapist. Like Joonas, Elisa says that she has 'always' had a sensitivity towards the uncanny. For example, she makes a reference to a 'spiritual friend' whom she used to play with as a child. She also says that she has always been sensitive to communications with the deceased. She writes that at the age of eight she could sense that her grandfather had passed away. When her mother received the sad news on the phone, Elisa told her not to answer the call because it will make her cry. Afterwards, Elisa describes her mother as having been 'astonished' by the warning. Elisa was not really shocked by the news as she says she felt that 'grandfather had it good now'. A further instance which has affected Elisa's process of coming to terms with such abilities concerns an out-of-body experience she had in the early 1980s as a young mother. During this experience, she 'was watching [my] body from the roofline', and there was 'no fear and no evil, just an incomprehensible freedom'. In this narrative, however, the experience is interrupted by a voice commanding her to return to her body. Elisa does not want to go back, but finally gives in as the voice commands her and says that she has a purpose, that she 'still has much to do'. Elisa then writes that she felt out of breath afterwards, and that all fear of death has since vanished.

Elisa has come to understand her sensitivity to see or sense things unobservable to others as a special ability; a skill to be used to receive knowledge across the boundaries of this world and the other world. Notably, in her adult life she has come to recognise this skill can be refined, and she has developed it in order to help others. Shortly after her out-of-body experience she started to engage in therapeutic work. In the 1990s she carried out mental support work with entrepreneurs before moving on to start an association which brings people together to 
discuss topics 'from birth to death and afterlife'. As a massage therapist, she has been developing a holistic treatment which also incorporates uncanny elements as Elisa discusses these themes with some of her customers. In Elisa's story different medical and healing discourses emerge as notable actants; for example, contemporary discourses of holistic health affect the ways in which she taps into the uncanny in order to help others. On the other hand, as will be shown, dominant medical discourses appear as equally powerful actants since Elisa's healing work is much about fighting the pathologising effects of discourses that treat the uncanny as error states of the mind.

Within the group sessions, the group has explored the future and the past. With the group, Elisa engages in making sense of the self and the world in a similar way as Joonas in his narrative. Elisa, however, also highlights herself as a helper of others as she assists people in training their senses and forming an understanding of a world in which both the uncanny and physical reality play an essential part. For example, she says that a customer's deceased father once entered the group session situation. With Elisa's assistance, the deceased was able to get a sign to the customer who recognised it as being from her father. Drawing on her personal experience of communicating with the dead, Elisa explains that 'the deceased want to tell us about life after death and sometimes, to forgive or be forgiven'.

Elisa's narrative thus introduces a therapist-actant who comes to act as a coordinator of uncanny encounters, helping people gain control over, manage and make further use of experiences that previously seemed unexplainable and 'out of place'. Through the sessions led by Elisa, the uncanny comes to affect people's understandings of themselves and the world in a new way. The uncanny then transforms from something strange and possibly disturbing into a therapeutic actant that provides a 'peace of mind'. Furthermore, such occasions affect and transform the therapist's professional path and mode of expertise. For example, when massage therapy customers wish to discuss spiritual matters, her professional act transforms by the adding of a spiritual layer into this treatment.

We might then go on to argue that therapeutic instances are not necessarily about people discovering some already existing truth or 'inner' self, an idea considered emblematic of New Age spirituality (Heelas, 1996: 18). Instead, truths about the self are established in collaborations between the therapist, her customers, the uncanny, material settings and other actants assembling in practices or 'improvising acts' of spiritual entrepreneurship (Hulkkonen, 2017: 5). Group sessions and treatments can be seen as events in a sense that through these gatherings, actants like customers, the therapist and the uncanny come to affect each other and transform; for example in the aforementioned example of channelling a message from a dead father Elisa's skill as a healer is actualised, as is the continuing existence of a loved one - and perhaps for example forgiveness - for the customer. This is how the therapeutic assemblage, involving the uncanny, 'hangs together'.

Elisa's narrative also highlights an effort to transform society on a wider scale, which traces back to experiences of stigmatisation she has endured in her social environment due to her sensitivity. She believes that she was misunderstood by 
her family, and says she had felt a deeper connection to her childhood spiritual friend than to her actual siblings. In fact, her spiritual friend provided her with mental support during feelings of loneliness that seemingly had to do with her special sensitivity. She eventually had to ask her spiritual friend to keep their distance since her parents had started to worry about her mental health.

Through such experiences of distinctness and loneliness, Elisa has come to recognise uncanny experiences as very alienating and widely misunderstood in a technoscientific society that tends to treat them as pathological. For herself, a series of particular uncanny encounters has led to a lifetime of work trying to normalise these experiences and help other experiencers come to terms with their special character. As she herself sees it,

People experience and sense many kinds of incidents. Before, they used to tell me about spiritual matters, fearing being labelled as crazy, and they asked me, like, in secret if they could talk to me about such things. I avoid using the term supernatural because to me, these things are natural things and events that belong in the circle of life. [...] Many people simply sense more finely, but they would not need medication but a down-to-earth approach to spiritual matters. Sure, there are also those who do need help from doctors and medication for their problems. Some people react in a defiant manner when somebody talks about "supernatural" things, spirits, or the deceased. This causes the most sensitive ones to question their own mental health and feel anxious about their uniqueness. My concern about how supernatural things are conceived in society and how alone highly sensitive people are, fearing stigmatisation, keeps me going [in therapeutic work].

The stigmatising character of uncanny experiences then comes to act as Elisa's primary motivation in carrying on her work with other experiencers (see also Koski, 2016). She emphasises the normality of such experiences; for example, she explicitly problematises the notion of 'supernatural', as do many other writers of the archive's letters. By narrating uncanny experiences as natural and intrinsic to some people, Elisa seeks to challenge and transform dominant pathologising discourses that have been influential in not only the sphere of modern medicine, but also everyday life. Elisa makes a critical remark about how people with uncanny experiences can needlessly be put on medication, but also admits that some people benefit from medical expertise. Thus, she does not try to prove medicine wrong, but rather suggests a widening of perspectives on human mind/body to cover spiritual matters, that is, she proposes the inclusion of uncanny actants in our conceptions of humanity, health and well-being.

Narrating personal experiences to representatives of institutionalised science can be understood as an effort to socially normalise uncanny experiences since these narratives are directed at people who are supposed to have the power to affect the social construction of knowledge and thus change the prevailing social structures that insistently seek to pathologise the individual experiencer. Through a (narrative of) lifelong experience of uncanny encounters, Elisa's knowledge 
has become experiential expertise. Elisa writes about how she has learned to talk about the uncanny in a generally understandable way, and she also invites the researchers to participate in one of her sessions. These actions can be understood as practices that seek to change the social perceptions of the uncanny experiences as deviant and/or matters of belief and thus not real. Writing to the researchers can be seen as a 'therapeutic event' in a sense that it seeks to establish new 'truths' about the world, although the outcomes and repercussions of such acts cannot be controlled by the writer and might be unexpected (cf. Latour, 1999).

In summary, the dominant scientific-rational worldview along with accompanying scientific discourses emerge in Elisa's narrative as actants that affect the perceptions of uncanny experiences and experiencers in society. In this context, active work on others and society by helping others and writing to researchers give shape to therapeutic assemblages which seek to provide people with comfort and peace of mind, as well as act upon dominant discourses and transform scientific and cultural ways of perceiving uncanny encounters.

While the main focus has been on Elisa's work on others and society, her narrative points to how uncanny encounters may involve active work on one's social relationships, work that transgresses the boundary between life and death. We now move on to investigate this particular aspect of uncanny experiences. In the next section we will illustrate how the uncanny comes to play a part in maintaining and nurturing continuous bonds.

\section{The uncanny and work on social relations}

Maija is a mother of three adult children. She is academically trained as an economist and has worked as a teacher and entrepreneur. Although retired, she is still in charge of a family-owned firm. Her father was a pilot in the Second World War and died in a plane crash when she was only five months old, yet Maija is convinced of her father's continuing presence and protection. After her mother's new marriage, Maija had a good life with her stepfather and siblings. She writes of her uncanny experiences, ranging from telepathic abilities to an ability to communicate with the deceased, and mentions her family's benevolent attitudes towards them. Most of the uncanny experiences she writes about are intertwined with social practices that seek to strengthen the social bonds between one's closest. Importantly, she does not draw a practical distinction between life and death, that is, this world and 'otherworld' in terms of social relationships. In this narrative the 'otherworld' does not denote a distinct 'place', but rather a continuum of human existence and care relations, and the fact that 'everything is well and goes on'. The 'otherworld' appears as an actant that arranges one's social assemblage in a way that is simultaneously old and new, as Maija's social relations persist, albeit mediated through a novel arrangement of actants.

Maija, like Joonas, describes the uncanny as an intrinsic part of her life, and like Elisa, she has both gone through uncanny experiences and made use of them to benefit other people. Through the uncanny Maija has gained a powerful sense of trust and gratitude towards continuous care relations which she seeks to turn 
into hope and comfort for others by volunteering in the local church and hospital. However, in contrast to Elisa, Maija's therapeutic assemblage is not so much about changing society as it is about preserving and stabilising one's personal social circle. As an actant, she resembles both a caretaker and the one who is being cared for; both a subject and object of the practice of care. Making no distinction between care of the living and the dead, she vividly describes her contacts with friends, relatives and neighbours and the signs they send her from 'afterlife'. These signs convince Maija of the well-being of her deceased loved ones who nevertheless remain very important actants in her life. For her, uncanny experiences have thus been empowering and positive, convincing her of the continuity of her most important social relationships.

Maija recounts examples about two friends whom she supported when they were dying. An important moment was when she got a guarantee of their status after death by receiving a sign. Reflecting the tendency of the uncanny to intertwine with the material context of human life and technology, the sign was mediated by candles that became lit. This can be seen as another 'therapeutic event' through which the transgressive and continuous social relation is actualised:

I was standing on her grave and the candle had gone out. I had that candle in my left hand and I was putting my right hand in my pocket to find the matches when the candle suddenly lit. 'Wonderful, Hilda, wonderful!' was my immediate reaction. I succeeded in putting the burning candle in the lantern, and for a while I was jumping, excited.

In another story, she speaks of feeling 'bottomless happiness' after receiving a sign from a deceased neighbour whose spouse had passed away before. In this story too the candle was decisive as an actant that propagated a hope that the neighbours would be able again 'to enjoy togetherness' in the afterlife.

Most of the signs of the uncanny actants which convince her of the well-being of her loved ones are visual. In these occurrences the lights can also turn on and off without perceptible cause. Moreover, she speaks of getting other visual signs that have warned her of a danger or threat to herself or others. For example, Maija writes that a flickering of lights, for which she had no explanation at the time of occurrence, turned out to be a sign of skin cancer that was consequently diagnosed early and healed. In this way, Maija's story resembles Joonas' account about the uncanny as work on oneself, as she has come to consider herself as 'loved and protected' as part of a larger bundle of relations that transcends the boundaries between material and non-material, human and non-human, life and death.

Last spring I was sitting in my study and solving sudokus and the tabletop lamp went off by itself. I thought it was a blackout but other lamps were working. After a while the lamp turned on by itself. The same thing the next day. And the next. And the next. I got nervous. And I said that I know something is wrong, but I don't know what it is, so stop that. I realised that I was receiving a message [...] At some point my husband was washing my back 
and said that I have a strange mole. It was black. I called a dermatologist. Melanoma. It was removed and it had not spread. The doctors said that never before had they found a melanoma at such an early stage. [...] I am thankful every day for being truly loved [...] I am convinced that my loved ones take care of me even after death, and most likely I will carry on the tradition.

Maija, like Elisa and Joonas, also acknowledges the stigmatising character of uncanny experiences, and in her own way is also politicised to change social perceptions of such experiences. However, we interpret her narrative also as reflecting a need of continuous confirmation of the 'truth' of the uncanny. Maija meticulously reports on how the candles work, in which situations they light up and in which they don't, and in general about the profoundly powerful and unexpected nature of uncanny occurrences, as evident in the previous description of the unlikely event of just one lamp going off repeatedly. In this way she 'validates' signs from the afterlife. This can be seen as further therapeutic work that seeks to actualise the existence of life after death and nurture the social relations that she finds dear to herself. Furthermore, in addition to feeling 'protected' in this life, Maija expresses a wish to herself keep looking after loved ones after her own death as well. This reflects the reciprocal character of care in Maija's personal circle, as she expresses a will to continue her care work and the maintenance of social relationships after her own death.

Maija's narrative also highlights the embodiment of the uncanny as part of therapeutic assemblages: how the presence of the uncanny, and thus the existence of the social relation, is confirmed through the body, by way of emotions and sensuous experiences rather than direct communication and interaction with uncanny beings. Maija recounts the way in which she recognised the presence and well-being - of her deceased stepfather in her body. After receiving word of her [step]father's death

I was crying a lot and was very anxious. On Saturday night I was crying and turning around and around in my bed, it was as if I had an iron belt around my chest. Just a horrible feeling. And then, suddenly, the feeling started from my head and moved down gradually, and I was gasping for breath like a fish on dry land, out of relief and happiness. I am sure that my dad wanted to tell me that self-pity and a heavy conscience are futile, that he was pleased with me and he was doing well.

Here Maija felt the presence of the deceased in her body in much the same way the traditional healers describe iconoclastic elements in the healing process (Taussig, 1993, see Bowman and Valk, 2012). The healers explain how they were able to make a 'diagnosis' by recognising and feeling the other's ailment in their own body and how they are able to take over the patient's pain while healing. This is also what happens in healing ceremonies with ancestral possession rituals (see Schmidt and Hutchinson, 2010), where the ritual subject is able to speak - and know the world - through the ancestor's often powerful voice. It is by mimesis ${ }^{4}$ and replication that the healer is able to cure. 
In summary, we interpret Maija's story being about the strengthening of social bonds beyond the binaries present in everyday perceptions of the world. Maija's dealings with the uncanny extend the reciprocal care relations into the domain of the 'otherworldly'. Making social bonds - instead of 'working them out by grief work' - is a theme that has recently been vividly studied and discussed (see Walter, 1999, 2007). People's ties with the deceased are interpersonal and multifaceted. As Maija's narrative demonstrates, they also manifest in bodily acts in addition to emotions and memories. Generally, by forging such ties, grieving persons construct a durable biography that enables them to integrate the memory of the dead into their ongoing lives. According to Walter (1999), the process by which this is achieved is principally considered a conversation between the living and the dead. Rather than being abandoned, the relationships with the deceased are renegotiated and sustained in one way or another. They can be a salient aspect of everyday life. In his phenomenological research of the mind, Ratcliffe (2017: 205-206) points out that the grieving process can include several embodied ways of experiencing and relating to the dead. Walter emphasises that the grief process hinges on talk more than feeling; and the purpose of grief includes moving on with, as well as without, the deceased. However, what is unique in Maija's narrative is the content and reciprocity of her way of relating to the dead, that of sustaining social relations.

\section{Conclusion: uncanny experiences as therapeutic events}

We have presented three autobiographical narratives of uncanny experiences and demonstrated not only how uncanny experiences are thoroughly social practices but how uncanny actants can become an integral part of people's therapeutic assemblages. The analysis of Joonas' narrative shows how uncanny experiences shape one's self-understanding and how they relate to self-care in the face of personal and political, local and global, (dis)continuities. Elisa's narrative focuses on how uncanny experiences have promoted actions of helping others, as well as politicised her to conduct transformative work on society. Maija's narrative is about working on personal social relations that transgress the impenetrable boundary between life and death. In many respects these narratives overlap, yet also reveal distinct ways of 'assembling' the uncanny into one's life and further into social discourses.

We argue that uncanny experiences can thus be understood as 'therapeutic events' that propagate social knowledge production; that is, new and/or old 'truths' in relation to oneself, the world and one's social relations. Importantly, we do not see uncanny experiences as a priori positive phenomena or being in essence about healing. In certain assemblages and situations they become productive of anxiety and chaos rather than healing and stability, yet even as such they can be 'worked with' in order to self-care and/or change society. Through an understanding of uncanny things as contingent 'actants' within people's therapeutic assemblages in everyday life - as they appear in the narratives above - we may seek to look beyond the question on the objective reality of such events and 
better focus on the role that such experiences play in the social shaping of reality and lifeworlds. After all, the uncanny vividly produces effects and materialises in the language, bodies, technologies and practices of human culture.

\section{Acknowledgements}

The authors would like to acknowledge support from the following projects: Mind and the Other, Academy of Finland, grant number 266573; Tracking the Therapeutic, Academy of Finland, grant number 289004; Crossing Borders for Health and Wellbeing, Kone Foundation and the Finnish Cultural Foundation. The authors specifically wish to thank Ülo Valk and Jon Mitchell and all our colleagues who have been involved in working on this edited book for sharing their thoughts and insights on earlier versions of this chapter.

\section{Notes}

1 In this work we want to avoid the term 'supernatural' due to its normative bias. The term 'uncanny' originates from Freud (1919), for whom it refers to ambiguous experiences that are simultaneously familiar and frightening. Despite its Freudian baggage, we think that the uncanny is the most suitable analytic concept for our work.

2 Peter Lamont (2007) has made a critical notion that in cognitive psychology uncanny experiences are typically reduced to 'paranormal beliefs' and/or explained as errors or anomalies in mental functions (see Rancken, 2017). In an evolutionary sense, in the cognitive theory of religion, the uncanny may be seen, for example, as an anomaly that stems from the human mind's tendency to anthropomorphize and animate its surroundings for adaptive purposes (Guthrie, 1993: 3-6; see also Boyer, 2001: 145-147).

3 According to Latour $(2005,72)$ things as actants 'affect' the world in a variety of ways: 'Things may authorize, allow, afford, encourage, permit, suggest, influence, block, render possible, forbid, and so on'.

4 Mimesis is an old healing technique by which threat and danger are warded off by means of imitating and consequently taming them.

\section{References}

Blanke, O. and Arzy, S. 2005. The out-of-body experience: Disturbed self-processing at the temporo-parietal junction. Neuroscientist 11, 16-24.

Bowman, M. and Valk, U. 2012. Vernacular Religion in Everyday Life. Oxon and New York: Routledge.

Boyer, P. 2001. Religion Explained: The Evolutionary Foundations of Religious Belief. New York: Basic Books.

Bury, M. 1982. Chronic illness as biographical disruption. Sociology of Health and Illness $4: 2,167-182$.

Bury, M. 2001. Illness narratives: Fact or fiction? Sociology of Health and Illness 23:3, 263-285.

Dein, S. 2012. Mental health and the paranormal. International Journal of Transpersonal Studies 31:1, 61-74.

Descola, P. 2013. The Ecology of Others. Chicago: Pricky Paradigm Press. 
Eliade, M. 1964. Shamanism; Archaic Techniques of Ecstasy. London: Arkada.

Freud, S. 1919. The 'Uncanny'. In English Translation: The Standard Edition of the Complete Psychological Works of Sigmund Freud, Volume XVII (1917-1919), edited by S. Freud. Harmondsword: Penguin Classics.

Guthrie, S. 1993. Faces in the Clouds: A New Theory of Religion. New York: Oxford University Press.

Heelas, P. 1996. The New Age Movement: The Celebration of the Self and the Sacralisation of Modernity. Oxford: Blackwell.

Heelas, P. and Woodhead, L. 2005. The Spiritual Revolution: Why Religion Is Giving Way to Spirituality? Oxford: Blackwell.

Honkasalo, M. 2017a. Hipaisuja ja ryminää - aineellisten ja aineettomien toimijoiden jäljillä. In Mielen rajoilla. Arjen kummat kokemukset, edited by M. Honkasalo and K. Koski. Helsinki: Suomalaisen Kirjallisuuden Seura, 196-234.

Honkasalo, M. 2017b. Neither real nor true. In Extending Experience through the Arts. Proceedings of Artistic Research in Performing Arts, edited by L. Rouhiainen. Helsinki: University of the Arts. https://nivel.teak.fi/carpa5/marja-liisa-honkasalo-neither-realnor-true-sharing-voices-in-the-intersubjective-space-and-beyond

Honko, L. 1960. Varhaiskantaiset taudinselitykset ja parantamisnäytelmä. In Jumin keko, edited by J. Hautala. Helsinki: Suomalaisen Kirjallisuuden Seura, 43-111.

Hulkkonen, K. 2017. Kanavointi ja jakautunut yrittäjyys - new age -henkisyyden ja yrittäjyyden yhdistämisen rajat ja mahdollisuudet. Elore 24:1, 1-20.

Josephson-Storm, J. 2017. The Myth of Disenchantment: Magic, Modernity and the Birth of Human Sciences. Chicago: University of Chicago Press.

Kapferer, B. 2002. Beyond Rationalism: Rethinking Magic, Witchcraft and Sorcery. New York: Berghahn Books.

Koski, K. 2016. Discussing the supernatural in contemporary finland: Discourses, genres, and forums. Folklore: Electronic Journal of Folklore 65, 11-36. https://www.folklore. ee/folklore/vol65/koski.pdf.

Lamont, P. 2007. Paranormal belief and the avowal of prior scepticism. Theory \& Psychology 17:5, 681-696.

Latour, B. 1992. Where are the missing masses? The sociology of a few mundane artifacts. In Shaping Technology-Building Society: Studies in Sociotechnical Change, edited by W. Bijker and J. Law. Cambridge: MIT Press, 225-259.

Latour, B. 1993. We Have Never Been Modern. Cambridge: Harvard University Press.

Latour, B. 1999. Pandora's Hope: Essays on the Reality of Science Studies. Cambridge and London: Harvard University Press.

Latour, B. 2005. Reassembling the Social - An Introduction to Actor-Network-Theory. Oxford: Oxford University Press.

Levi-Strauss, C. 1968. The Savage Mind. Chicago: University of Chicago Press.

Luhrmann, T. 2018. The sound of madness. Harper's Magazine, June, 45-54.

Mauss, M. 1902/2001. A General Theory of Magic. London: Routledge.

Mauss, M. 1909/2003. On Prayer. Oxford and New York: Berghahn.

Mobbs, D. and Watt, C. 2011. There is nothing paranormal about near-death experiences. Trends Cognitive Sciences 15:10, 447-449.

Mol, A. 2002. The Body Multiple: Ontology in Medical Practice. Durham: Duke University Press.

Raij, T., Valkonen-Korhonen, M., Holi, M., Therman, S., Lehtonen, L. and Hari, R. 2009.

Reality of auditory verbal hallucinations. Brain 132:11, 2994-3001.

Rancken, J. 2017. Yliluonnollinen kokemus. Tampere: Vastapaino. 
Ratcliff, M. 2017. Real Hallucinations. Boston: MIT Press.

Sansi, R. 2013. The latour event: History, symmetry and diplomacy. Social Anthropology $21: 4,448-461$.

Schmidt, B. 2016. The Study of Religious Experience: Approaches and Methodologies. Bristol: Equinox.

Schmidt, B. and Hutchinson, L. (eds.) 2010. Spirit Possession and Trance, New Interdisciplinary Perspectives. London and New York: Bloomsbury.

Siikala, A.-L. 1978. The Rite Technique of the Sibirian Shamans. Folklore Fellows Communications 220. Helsinki: Academia Scientiarum Fennica.

Silvanto, J. 2015. Why is "blindsight" blind? A new perspective on primary visual cortex, recurrent activity and visual awareness. Consciousness and Cognition 32:2, 15-32.

Taussig, M. 1993. Mimesis and Alterity. New York: Routledge.

Tucker, J. 2004. New age healers and the therapeutic culture. In Therapeutic Culture: Triumph and Defeat, edited by J. Imber. New Brunswick and London: Transaction, $153-169$.

Turner, V. 1968. Drums of Affliction. Oxford: Clarendon Press.

Viveiros de Castro, E. 2004. Perspectival anthropology and the method of controlled equivocation. Tipiti: Journal of the Society for Anthropology of Lowland South America $2: 1,1-22$.

Walter, T. 1999. On Bereavement. The Culture of Grief. Berkshire: Open University Press. Walter, T. 2007. Modern grief, postmodern grief. International Review of Sociology 17:1, 123-134.

Weber, M. 1922/1967. Essays in Sociology. New York and London: Routledge \& Kegan Paul. 